Acta Hispanica (2015) 20: 79-89

\title{
JOAN FUSTER Y JULIÁN MARÍAS: DOS INTELECTUALES FRENTE A LA TRANSICIÓN ESPAÑOLA A LA DEMOCRACIA
}

\author{
ROBERTO RODRÍGUEZ MILÁN
}

\author{
Hellenic Open University
}

\begin{abstract}
Resumen: Desde el otoño de 1975 el cambio político en España ya constituye una opción tangible. Ante el mudable panorama ibérico, poblado de miedos, incertidumbres y esperanzas, algunos intelectuales dan un paso al frente en la que consideran su función social y tratan de entablar un diálogo con la sociedad de su tiempo, ofreciéndole una interpretación personal de la realidad política y social del momento. Destacamos aquí el protagonismo dispar de dos intelectuales veteranos en la disidencia frente al régimen dictatorial del general Franco: el escritor Joan Fuster y el filósofo Julián Marías, que mediante sus constantes ensayos "de urgencia", objeto de estudio de esta comunicación, redoblan sus esfuerzos para ver de contribuir a la conformación de una opinión pública informada sobre el pasado y comprometida con el presente y el futuro, capaz de volver a convertirse en sujeto activo de la historia.
\end{abstract}

Palabras clave: transición, Joan Fuster, Julián Marías, ensayismo, reflexión nacional

\begin{abstract}
From autumn 1975 onwards, political change becomes a tangible possibility in Spain. In the face of a quite unpredictable scenario for the Iberian country, filled with concerns, uncertainties and expectations, many intellectuals take a step forward in what they regard as their social role, attempting to engage a dialogue with the society they belong to by proposing a personal reading of the political and social reality of the time. We highlight here the dissimilar prominence of two intellectuals, both of them veteran in their dissent versus General Franco's dictatorship: the writer Joan Fuster and the philosopher Julián Marías. Through their constant "emergency" essays which are here under consideration, these two intellectuals intensify their effort so as to contribute to shape a public opinion informed about the past and committed with the present and the future, able to become an active subject of History once again.
\end{abstract}

Key words: Transition to democracy, Joan Fuster, Julián Marías, essayism, reflecting upon the nation

"Considero a Flaubert y a Goncourt responsables de la represión que siguió a la Comuna porque no escribieron una sola palabra para impedirla. Se dirá que no era asunto suyo. Pero ¿es que el proceso de Calas era asunto de Voltaire? ¿Es que la condena de Dreyfuss era asunto de Zola? ¿Es que la administración del Congo era 
Joan Fuster y Julián Marías: dos intelectuales frente a la transición española a la democracia

asunto de André Gide? Cada uno de estos autores, en una circunstancia especial de su vida, ha medido su responsabilidad de escritor."1

Al término de la guerra civil española, en 1939, sólo el compromiso de algunos intelectuales, entre los que destaca el filósofo Julián Marías Aguilera (1914-2005), parece impedir la aniquilación de la corriente ideológica y cultural liberal que arranca con el regeneracionismo y la Generación del 98, que prolonga José Ortega y Gasset, y que había hecho de la reflexión nacional en torno a España uno de sus objetivos principales. La contienda fratricida y su resultado también reducen a un silencio casi total al catalanismo, fenómeno de envergadura tal vez menor que el anterior pero no menos consolidado, trascendental o dinámico; pese a todo, también en este ámbito se generan espacios de resistencia intelectual y se retoma una reflexión nacional alternativa desde la posguerra, en todo lo cual sobresale el escritor Joan Fuster i Ortells (19221992). Desde diferente horizonte ideológico, lingüístico y, en parte, también cultural, la labor intelectual de Marías y Fuster alcanza la madurez en los años sesenta, cuando ambos logran poner de manifiesto que, pese al régimen político imperante y sus designios, el género ensayístico que cultivan ofrece cauces de libertad de expresión, y también que la vieja cuestión de la identidad nacional permanece abierta, se perfila como una de las grandes inquietudes de la época y es susceptible de recibir lecturas muy dispares. En los años setenta, la crucial coyuntura española lleva a ambos intelectuales a medir su responsabilidad de escritores a través de una notable producción de ensayos "de urgencia" en los que manifiestan un compromiso neto con la democratización de la sociedad a la que consideran pertenecer y con la defensa de la identidad nacional, histórica y presente, de dicha sociedad. Lo que sigue es, por motivos de extensión, una apretada síntesis de dicha reflexión "de urgencia".

Entre 1931 y 1936 Julián Marías estudia en la Facultad de Filosofía y Letras de Madrid, donde conoce a algunas de las personalidades más relevantes de la cultura liberal de la época y entabla amistad con su profesor y mentor José Ortega y Gasset. En la inmediata posguerra civil, el pasado en las filas del ejército republicano, la profesión de fe liberal y los vínculos con Ortega convierten a Marías en una víctima más del hostigamiento dictatorial. Éste solo se mitiga cuando el franquismo se ve obligado a limar sus aristas políticas para evitar potenciales represalias de los vencedores de la Segunda Guerra Mundial, y la atenuación de la represión da a Marías cierto margen de maniobra para su acción intelectual. Las inquietudes que la motivan y los objetivos que la guían y vertebran aparecen en múltiples escritos desde los años cincuenta: la identidad nacional y cultural española; la continuidad, pese a la guerra civil, de la cultura inaugurada por la Generación del 98; y la denuncia de las múltiples y prolongadas tergiversaciones de la memoria histórica de España.

${ }^{1}$ Jean-Paul SARTRE, cit. in: Carlos Altamirano, Intelectuales: notas de investigación, Bogotá, Grupo Editorial Norma, 2006, 36, asequible en: http://neorrabioso. blogspot.gr/, fecha de consulta: 17 de julio de 2015.

80 | Acta Hispanica, Hungría 20: 79-89, 2015, ISSN: 1416-7263 
Aunque a mediados de los años sesenta el centro de gravedad de los escritos de Marías se desplaza hacia la producción de obras de carácter filosófico y relacionadas con sus viajes y estancias en el extranjero ${ }^{2}$, su labor de reflexión sobre la nación no cesa de madurar, como pondrá de relieve su fecunda actividad en la década de los años setenta, cuando las nuevas circunstancias históricas que atraviesa España centran su interés y lo impulsan a una intensa actividad en dos ámbitos: en el institucional, acepta su nombramiento como senador de designación real, con lo que participa activamente en el proceso político-institucional de transición a la democracia y se implica en la vida pública española como no habían logrado hacerlo sus mentores de preguerra; y en el ámbito intelectual, Marías se dedica a reflexionar sobre el presente y el posible devenir nacionales a través de numerosos artículos ensayísticos en publicaciones periódicas, destinados a informar y orientar a la opinión pública española, a fin de hacerla tomar conciencia de los retos y riesgos que se le presentan y ante los cuales deberá tomar posición.

Como de costumbre en Marías, el tratamiento e intención de los temas, así como el género escrito y el soporte material elegidos para esta actividad concreta, se corresponden con la figura del intelectual y su función social tal como las prefigurara la tradición liberal desde la Generación del 98 hasta la guerra civil. Fiel también a su lógica de ver de impedir que sus ensayos caigan fácilmente en el olvido, Marías reunirá casi 200 de ellos en cuatro libros que cubren cronológicamente todo el proceso de transición de la dictadura a la democracia, desde poco antes de la muerte del general Franco hasta la retirada de Adolfo Suárez, uno de los principales artífices del cambio político e institucional, en vísperas de un golpe de Estado frustrado y del acceso al poder, por primera vez en la historia de España, de un partido socialista; dichas cuatro recopilaciones son La España real (1976), La devolución de España (1977), España en nuestras manos (1978) y Cinco años de España (1981).

La trayectoria de Marías como escritor es larga y desde las décadas anteriores es blanco de múltiples ataques procedentes de diversos flancos ideológicos; empero, "su momento estelar como pensador de la realidad española llegaría con la transición a la democracia", 3 cuando la referida tetralogía sobre "la España real" alcanza un gran éxito y repercusión social. ${ }^{4}$

El compromiso de Marías con el proceso de cambio político se revela coherente con su pensamiento precedente. Así, toda la reflexión vertida en dicha tetralogía atiende sin tregua a un axioma perfilado en el ensayismo de la etapa anterior: la interpretación de la historia de España debe atender a la realidad, lo cual implica contemplar la memoria del pasado en su integridad; este conocimiento permite comprender el pasado y el presente, ofrece lecciones sobre los errores a evitar -como, por ejemplo, la guerra civil-, invalida

\footnotetext{
2 Julián MARÍAS, Una vida presente: Memorias 2 (1951-1975), Madrid, Alianza, 1989, 233-440.

3 José María BENEYTO, Tragedia y razón: Europa en el pensamiento español del siglo XX, Madrid, Santillana, 1999, 227.

${ }^{4}$ Ello se refleja a menudo en críticas que Marías recoge en su propia obra, ver p. ej. España en nuestras manos, Madrid, Espasa Calpe, 1978, 82-3, 245-9, y Cinco años de España, Madrid, Espasa Calpe, 1981, 199-202.
} 
Joan Fuster y Julián Marías: dos intelectuales frente a la transición española a la democracia

las manipulaciones de diverso color y procedencia, y permite vislumbrar el futuro y diseñar proyectos de porvenir consecuentes, coherentes y viables.

En relación con el presente, la realidad que observa Marías es la de la continuidad histórica de España: la transición a la democracia supondría una discontinuidad sólo con la historia "superficial" o "externa", encarnada por el régimen dictatorial, pues la continuidad con la "intrahistoria" o "ser histórico" del país en ningún momento se ha visto comprometida, $y$, en última instancia, habría sido precisamente la continuidad con la cultura de la tradición liberal lo que habría garantizado estas dos trayectorias de signo contrario. ${ }^{5}$ De esta percepción se deriva inevitablemente el proseguir la reflexión sobre la "España real" evitando -y denunciando- los escollos que puedan presentar su contrapartida, la "España oficial", o sectores de la sociedad aquejados de partidismo, particularismo o abstracción: "Mi posición personal tenía algunos rasgos muy precisos. Mi deseo de un cambio profundo en la vida política española era sumamente vivo, y de extremada antigüedad: en rigor, lo tenía desde que se torció el rumbo de la República, digamos desde 1934; con plena concreción, desde el establecimiento de un régimen que nunca me pareció aceptable, al terminar la guerra civil. Pero [...] no me interesaba cualquier cambio, sino el que reflejara la realidad del país y asegurara un máximo de libertad y concordia." 6

Una idea que atraviesa los escritos de la tetralogía es que la reorganización democrática del Estado y la sociedad triunfa gracias a la política de Adolfo Suárez, caracterizada por tres rasgos decisivos: el imperativo de una apertura liberalizadora previa a la democratización; la voluntad de superación del esquema polarizador entre derechas e izquierdas, a través de un talante personal integrador; y la plena restauración y consolidación de la monarquía como institución moderadora por encima de los partidos políticos.

A su vez, entre las contribuciones más importantes de Marías a la reflexión sobre el proceso de transición se cuentan sus consideraciones sobre tres aspectos de la vida pública: la figura del rey y el papel de la nueva monarquía española en la vida nacional; el texto constitucional; y la cuestión de las lenguas de España y la defensa de la española. ${ }^{7}$ El trasfondo vertebrador de dichos tres temas lo constituye, no obstante, otra inquietud: desde la víspera del cambio de régimen, la cuestión crucial y más apremiante que observa Marías es la de la estructura político-administrativa y territorial de España. Esta última acusa la presión procedente de dos polos, el centralismo homogeneizador a ultranza y el particularismo separatista, principalmente el catalanista, polos que el intelectual considera como "los dos grandes escollos de la vida española en el último siglo", si bien el problema que él considera más serio "es el regional, allí

\footnotetext{
${ }^{5}$ BENEYTO, op. cit., 228-9.

${ }^{6}$ MARÍAS, Una vida presente 2, op. cit., 400.

${ }^{7}$ MARÍAS, Una vida presente: Memorias 3 (1975-1989), Madrid, Alianza, 1989, 71-8.

${ }^{8}$ MARÍAS, La España real, Madrid, Espasa Calpe, 1976, 27-28.
} 
donde se produce una seudomórfosis [sic] 'nacionalista' que puede perseguir una insidiosa perturbación de la estructura nacional de España."9

El proyecto que Marías propone y puede ya plantear sin las cortapisas de la censura, consistiría en desplegar la esencial pluralidad española: "como creo que la sociedad de cada nación, concretamente la de España, es regional, soy partidario de un amplio sistema de autonomías [...] es menester que las regiones estén presentes en la estructura del Estado nacional, que se encuentren y convivan en la unidad de España."10 A continuación, España debería reintegrarse en Europa, a la que pertenece de pleno derecho, incluso más que las naciones vecinas a causa de su multisecular voluntad de ser europea. Sin embargo, el país ibérico no debería detenerse en este punto, pues como nación históricamente "transeuropea" tiene responsabilidades al otro lado del Atlántico que, en último término, se hacen extensivas a la totalidad de Occidente. En otras palabras, el proyecto de Marías durante la transición a la democracia consiste en "no renunciar a nada. A la prodigiosa variedad de España, a la pervivencia dentro de ella de modalidades diferentes, vivas, entusiastas, de lenguas particulares que pueden alcanzar perfección y añadir matices valiosos a una cultura muy compleja. A una lengua común, la que empezó por ser castellana y fue muy pronto española, cuyo destino histórico fue convertirse en la expresión de una de las culturas más creadoras y universales de Occidente. A una empresa histórica que contribuyó decisivamente a la formación de Europa y de la conciencia europea global, y trascendió de los límites continentales europeos para crear la primera gran comunidad de pueblos heterogéneos después del Imperio romano."11

Al término de la guerra civil, en que no participa, Joan Fuster estudia Derecho en la Universidad de Valencia pero opta por dedicarse en exclusiva a su pasión literaria, que cultiva tanto en catalán como en castellano, al tiempo que realiza un viraje ideológico que lo lleva del "españolismo ambiental" al catalanismo comprometido. La penuria sociocultural de su entorno, derivada del carácter de la dictadura de Franco, pero también de las deficiencias históricas y actuales del catalanismo, impulsan a Fuster a escribir aquello que hubiera deseado leer pero no existía. ${ }^{12}$ Tras una etapa de indagación y reflexión, con importantes intercambios con el exilio catalán en México, la obra capital de ese proceso intelectual es Nosaltres, els valencians (1962), ensayo en que Fuster establece que Valencia es históricamente parte integrante de la nación y cultura catalanas; determina los problemas pretéritos y presentes, internos y externos, para la plena asunción y expresión de dicha identidad; y afirma la necesidad de una recuperación nacional "pancatalana" que debe comenzar por la lengua nacional común y aspirar a lograr la independencia nacional de los "Países Catalanes".

9 MARÍAS, Cinco años de España, op. cit., 153-154. Para más alegatos de Marías contra los particularismos separatistas en este período, ver p. ej. Una vida presente 3, op. cit., 129-30, 297-300. ${ }_{10}$ MARÍAS, La devolución de España, Madrid, Espasa Calpe, 1977, 164, 170-171. Subrayado del autor. ${ }^{11}$ MARÍAS, Cinco años de España, op. cit., 158.

12 Joan FUSTER, Un país sense política (1976), Alzira, Bromera, 1995, 23-24. Salvo que se indique lo contrario, la traducción al castellano es nuestra. 
Joan Fuster y Julián Marías: dos intelectuales frente a la transición española a la democracia

Desde principios de los años setenta se consolida el reconocimiento de la labor literaria de Fuster en los ámbitos de las lenguas española y catalana, y ante la inminencia del cambio de régimen político, con todas las posibilidades que de ello se derivarían, el compromiso civil del escritor se hace efectivo en dos ámbitos: por un lado, en el impulso de iniciativas políticas, como, por ejemplo, la redacción del Estatuto de Elche, un proyecto nacionalista de autonomía para Valencia; y por el otro, en la multiplicación de sus colaboraciones en medios de publicación periódicos de toda España, que en ocasiones llegan a alcanzar la veintena de artículos mensuales. ${ }^{13}$ Caracterizados por una libertad de expresión sin precedentes, los ensayos más destacados del período de transición a la democracia aparecerían en las recopilaciones Contra Unamuno y los demás (1975), Un país sense politica (1976), "El blau en la senyera" (1977), Destinat (sobretot) a valencians (1979), "País Valencià, per què?" (1981), Ara o mai (1981), y Punts de meditació (Dubtes de la "Transición”) (1985).

Los tres grandes frentes de reflexión que plantea este ensayismo son la consideración crítica del nacionalismo español, sobre todo, pero no exclusivamente, el de la tradición liberal desde la Generación del 98; la crónica de urgencia sobre las circunstancias sociales y políticas a que da lugar el proceso de transición a la democracia desde mediados de los años setenta; y la reiteración de las tesis pancatalanistas contenidas en su ensayismo de las décadas precedentes con el fin de difundirlas, como propuesta, entre la opinión pública.

El nacionalismo español y, en su seno, la lectura de la historia de España que hace la tradición liberal es una de las cuestiones que más preocupan e indignan a Fuster durante la transición, a medida que se hace patente su impronta en el talante de las transformaciones conducentes al cambio político, concretamente en el terreno de la organización político-administrativa y territorial del Estado emergente. Contra Unamuno y los demás (1975) recopila una treintena larga de ensayos en castellano publicados entre 1970 y 1974 en que Fuster deja bien claro el núcleo de su crítica contra la reflexión sobre España que realiza dicha tradición liberal, a saber, que tiene la pretensión de hacer historiografía cuando en realidad lo que aporta no es sino ensayismo, el cual, por añadidura, se revela profundamente irracional e ideológicamente agresivo: ${ }^{14}$ " ¿'Historia', pues? Nada de eso: la vieja enconada discusión acerca del 'ser de los españoles', que es, en definitiva, un planteamiento militante, ideológico de pies a cabeza, o de cabo a rabo, marginal $-\mathrm{O}$, a lo sumo, 'tangente'- a los intereses de la 'Historia'. No se intenta tanto aclarar el pasado como preparar un futuro. $\mathrm{Y}$ el futuro que quisieron preparar Menéndez Pelayo, Unamuno, Menéndez Pidal, Ortega, Sánchez Albornoz y Américo Castro, por encima y por debajo de las apariencias, tiene mucho en común.

13 Josep BALLESTER i Antoni FURIÓ, Joan Fuster, 1922-1992: 10 anys després, Barcelona, Institució de les Lletres Catalanes, 2002, 17-18.

${ }^{14}$ Joan FUSTER, Contra Unamuno y los demás, Barcelona, Edicions 62, 1975, 25-7, 81-82. 
Conjuntamente, es una perspectiva que, en su verdad recalcitrante y agresiva, a mí, personalmente, no me gusta."15

A su modo de ver, los escritos de la tradición liberal resultan estériles como interpretaciones históricas, pero refuerzan una construcción ideológica, "España", que históricamente nutre el nacionalismo de Estado, intoxica al común de la sociedad hispánica, incluida la valenciana, conduce al fracaso las tentativas desprejuiciadas y científicas de abordar la cuestión y sólo permite el cultivo de un "singular género literario llamado 'Historia de España"', caracterizado por sus altas dosis de fabulación. ${ }^{16}$

En este punto parece oportuno un inciso para observar el incremento de la agresividad de Joan Fuster contra la tradición liberal a través del ejemplo concreto que supone Julián Marías. Fuster no deja de hacerse eco de la actividad del segundo, si bien en tonos diferentes que ponen de manifiesto tanto el creciente eco social de Marías como la hostilidad de Fuster ante lo que éste representa, ante su implantación social y ante su alcance ideológico y, tal vez, político-administrativo. Dos ejemplos concretos permitirían ilustrarlo. En una entrevista de 1966, Fuster comenta la aparición del ensayo "Consideración de Cataluña" de Marías y descalifica, en tono moderado, su aportación intelectual a la comprensión del "hecho catalán": "Era lógico que el libro de D. Julián Marías consiguiese una crítica favorable de D. Fernández de la Mora, su actitud frente a Cataluña tenía que ser similar a la de D. Julián Marías. O peor. Marías paseó por Cataluña sin enterarse de nada, o de casi nada. Pero, por lo menos, hizo un esfuerzo de eso que en Madrid llaman 'comprensión'. El señor de la Mora no se molestó ni siquiera en emprender el paseo. Ya van arregladas las mesnadas carpetovetónicas, con mentores así..."17 Más de una década después, en 1978, cuando Marías se muestra particularmente activo y comprometido con el proceso de transición a la democracia tanto en lo institucional como en lo mediático, Fuster concluye una de sus reflexiones con una descalificación total del intelectual liberal y lo que éste representa ideológicamente: "Las corsarias es un texto carpetovetónico tan importante como el Quijote o más. Don Julián Marías, pongo por caso, deriva más de Las corsarias que del Quijote. 'Banderita tú eres roja, banderita tú eres gualda..." 18; crítica que preludia un ataque más furibundo: “¿Castro, Pidal, Albornoz? No serán ni Laín, ni Tovar, ni Marías la alternativa. Y eso que el profesor Tovar continúa tan nazi como cuando era jovencito. Laín comienza, y muy tarde, a comprender qué es ser liberal. Marías es una colosal proposición a la risa."19

\footnotetext{
15 Ibídem, 27-28.

16 Ibídem, 82-83.

${ }^{17}$ Joan FUSTER, De viva veu: entrevistes (1952-1992), Catarroja, Afers, 2003, 71.

18 Joan FUSTER, Destinat (sobretot) a valencians, Valencia, Eliseu Climent, 1979, 93. Las corsarias es una zarzuela de F. Alonso, estrenada en 1919; Banderita pertenece a la canción "Soldadito español", que acostumbra a ponerse en España con ocasión de los desfiles militares y las juras de bandera. 19 Joan FUSTER, Breviari cívic, Barcelona, Edicions 62, 2001, 77. Para más comentarios sobre la percepción que Fuster tiene de Marías, ver Josep M. COLOMER, Espanyolisme i catalanisme: la idea de nació en el pensament polític català (1939-1979), Barcelona, L' Avenç, 1984, 168, 172-173.
} 
Joan Fuster y Julián Marías: dos intelectuales frente a la transición española a la democracia

Marías parece recoger el guante, aunque muy puntualmente y con su característica tendencia a aludir sin nombrar, cuando lleva a cabo su crítica del particularismo separatista, centrada, como se recordará, en el catalanista, y pasa por el tamiz crítico de su propia tradición intelectual los conceptos de "País Valenciano" y "Países Catalanes" a cuya definición y difusión a contribuido decisivamente Fuster. Señala Marías: "[la palabra 'país'] aunque no es muy antigua en español, se remonta al siglo XVII; se usa ampliamente 'País Vasco' (adaptación sin duda de 'Pays Basque', pero que ya ha adquirido vigencia en el uso español, y que los vascos aprueban). Aunque es término muy reciente, y creo que no muy afortunado, se dice con frecuencia 'País Valenciano'. Los catalanes usan en los últimos tiempos la expresión 'els Països catalans', pero es curioso que rarísima vez llaman 'país' a la propia Cataluña, lo cual deja flotando un tufillo 'imperialista' en aquella denominación, que a veces inquieta a los vecinos." 20

Por lo demás, Marías no renuncia a debatir sobre Cataluña y el catalanismo, aunque parece optar por otros interlocutores y otros términos. Así, en el prólogo a la segunda edición de Consideración de Cataluña (1974), el filósofo resume los términos de la polémica sostenida con el intelectual y ensayista catalán Maurici Serrahima i Bofill, el cual había afirmado la condición nacional de Cataluña en 1967 con su réplica titulada Realidad de Cataluña: respuesta a Julián Marías. ${ }^{21}$

Pero es que Marías y Fuster no combaten por sus ideas en igualdad de condiciones: de salida, el ideario del primero goza de una resonancia política, intelectual y social considerables, y aun parece impregnar el texto constitucional que se elabora en 197822; en segundo lugar, a lo largo de todo el siglo XX, el catalanismo que ha preocupado a los representantes del nacionalismo español, sobre todo a los de la tradición liberal, Marías incluido, es el irradiado por Cataluña, y por no otros ámbitos, como el valenciano, que, en efecto, parece revelarse tan periférico como denuncia Fuster; en tercer lugar, durante la transición a la democracia se hace explícito el desinterés del nacionalismo catalán hegemónico en Cataluña por las solicitudes pancatalanistas procedentes de Valencia, en tanto que la izquierda barcelonesa incluso arremete contra Fuster; ${ }^{23}$ y en cuarto lugar, el pancatalanismo valenciano tampoco logra articularse ni política ni socialmente ${ }^{24}$ y acusa la dura contestación de las clases dirigentes locales, que convierten a Fuster en blanco

\footnotetext{
20 MARÍAS, España en nuestras manos, op. cit., 242.

${ }^{21}$ MARÍAS, Una vida presente 2, op. cit., 230-1.

22 José Ignacio LACASTA ZABALZA, "Tiempos difíciles para el patriotismo constitucional español", in: Cuadernos electrónicos de filosofía del derecho, 2, 1999, asequible en: http://www.uv.es/ CEFD/2/Lacasta.html, fecha de consulta: 15 de junio de 2003.

${ }^{23}$ FUSTER, Un país sense politica, op. cit., 88-9, Miquel ALBEROLA i Vicent MARTÍ, Fuster sabàtic, Altea, Aigua de Mar, 1994, 57-58.

${ }^{24}$ Isidre CRESPO, Introducción, Joan Fuster: raons i paraules, Barcelona, Hermes, 1999, 160-161.
} 
de una agresiva hostilidad que se despliega en medios de comunicación periódicos entre 1975 y $1982 .{ }^{25}$

Este cúmulo de circunstancias y la consiguiente demolición sistemática de todas las esperanzas que Fuster había depositado en la consecución de un proyecto de regeneración nacional pancatalanista se hacen patentes con celeridad y el escritor las denunciará a lo largo de todo el período en ensayos de tono crecientemente provocador ${ }^{26}$-los ya referidos Un país sense política, "El blau en la senyera", Destinat (sobretot) a valencians, Ara o mai, "País Valencià, per què?" y Punts de meditació-.

En este ensayismo Fuster aborda la cuestión de la separación de la nación catalana en diversas unidades arbitrarias, ya denunciada desde principios de los años sesenta, separación que persiste tras la desaparición de la dictadura de Franco, dado que en la transición a la democracia la noción de "Países Catalanes" está ausente de la ordenación jurídica y legal del nuevo régimen político, y las "concesiones autonómicas" no están diseñadas para resolver la cuestión, sino para agudizarla aún más. El adversario más intransigente a la institucionalización de los "Países Catalanes" es, como siempre, el Estado español, cuyo nacionalismo comparte una parte sustancial de la sociedad hispánica, incluida la valenciana. ${ }^{27}$ De todo lo anterior se deriva el deterioro de la lengua privativa de todos los catalanes, cuya supervivencia se ve gravemente comprometida. Por añadidura, Fuster observa una irresponsable e inexcusable inhibición de Cataluña frente a su propia "periferia nacional" y una voluntaria reducción de sus aspiraciones nacionales a mero regionalismo; Cataluña no se decide a aceptar el doble desafío consistente en enfrentarse al nacionalismo de Estado y en asumir y defender la nacionalidad catalana "al completo", más allá de su ámbito territorial estricto, pese a que la solución al "problema del País Valenciano" pasa por unos "Países Catalanes" convergentes a partir de sus propios "hechos diferenciales". ${ }^{28}$ Fuster también expresa su frustración ante la política concreta, ante las deficiencias del nacionalismo valenciano y la izquierda política local, así como ante la progresiva despolitización de la juventud, y considera la "España de las Autonomías" como una maniobra lampedusiana del Estado y de prácticamente todas las fuerzas políticas para desbaratar las aspiraciones pancatalanistas.

25 Tanto es así que Fuster confiesa en 1978 que normalmente publica sus escritos fuera de Valencia “porque, aún hoy, en el País Valenciano, soy un 'personaje conflictivo'. Lo era con el franquismo, era natural. Lo soy, parece, con la democracia", ver FUSTER, De viva veu, op. cit., 221. Sobre el acoso mediático contra Fuster, ver Josep Maria MUÑOZ PUJOL, El falcó de Sueca, Barcelona, Ecsa, 2002, 223-231, 240.

26 Toni MOLLÀ, Joan Fuster: converses inacabades, Valencia, Tàndem, 1992, 99-100.

${ }^{27}$ FUSTER, Un pais sense politica, op. cit., 159-60.

28 Joan FUSTER, Pamflets politics, Barcelona, Empúries, 1985, 89. A la serie de cuatro artículos titulada "País Valencià, per què?" (1981), Fuster agregará en 1982 una breve introducción y un epílogo; bajo esta forma serán recogidos tres años más tarde en la obra Pamflets polítics. 
Joan Fuster y Julián Marías: dos intelectuales frente a la transición española a la democracia

Fuster será víctima de dos atentados criminales de los que saldrá indemne ${ }^{29}$, y no se dejará intimidar, como pone de manifiesto la constante publicación de escritos que mantienen la temática nacional y nacionalista, el tono crítico y mordaz, y el carácter de urgencia, si bien con un desencanto creciente, como creciente es su aperturismo a actores sociales no catalanes pero susceptibles de convertirse en aliados del proyecto pancatalanista. ${ }^{30}$ En 1982, sin embargo, sus esfuerzos y esperanzas naufragan cuando el Estatuto de Autonomía consagra la denominación "Comunidad Valenciana” y oficializa la designación de "valenciano" para la lengua local, a resultas de lo que Fuster percibe como un pacto entre los grandes partidos políticos de ámbito estatal y los representantes locales del valencianismo anticatalanista. ${ }^{31}$

No resulta aventurado afirmar que una parte de la obra ensayística de Marías es un referente obligado para comprender las inquietudes y aspiraciones de una parte del mundo intelectual y cultural español que, durante la larga etapa de la dictadura franquista, quiso ver en su pasado inmediato una Arcadia cultural, no para refugiarse en ella o añorarla, sino a la que era posible y necesario insuflar vida; dadas las circunstancias del franquismo, el hecho de que esta cultura medrara implica que tenía vigencia en sectores no desdeñables de la sociedad, y lo mismo parecen poner de manifiesto la importancia del ensayismo de Marías en el lento y delicado proceso de la transición a la democracia, así como la influencia del filósofo en la intelectualidad posterior a él. 32 Por su parte, la gran ambición concreta de Fuster que lo lleva a ensayar sin tregua sobre la nación es que "no quiero morirme sin haber dejado en funcionamiento y en forma en el País Valenciano, unos cuantos equipos de intelectuales y de no intelectuales capaces de remover -o al menos de intentarlo- esta sociedad en perpetua somnolencia digestiva". ${ }^{33}$ De lo que no cabe duda es que Fuster logra remover a su sociedad e incluso logra generar seguidores de su labor; además, su obra crea "escuela", porque marca a más de una generación de autores valencianos, muchos de los cuales adoptan el molde expresivo del ensayo y también muchas de sus ideas, entre las que destaca la de la primacía del método de

\footnotetext{
${ }^{29}$ En junio de 1971 hace explosión un artefacto en la editorial Tres i Quatre, que había publicado parte de la obra de Fuster; en 1978 y 1981 se producen sendos atentados con bombas contra el domicilio de Fuster, de los que sale indemne; han quedado impunes, ver MUÑZ PUJOL, op. cit., 162.

${ }^{30}$ Joan FUSTER, Ara o mai, Valencia, Eliseu Climent, 1981, 51, 58.

31 MOLLÀ, op. cit., 88.

32 Para dicha influencia, ver Amelia CASTILLA, "Una España cicatera", asequible en: http://www.javiermarias.es/2005/12/en-la-muerte-de-julin-maras.html, fecha de consulta: 17 de diciembre de 2005, y VV. AA. Un siglo de España: homenaje a Julián Marias, Madrid, Alianza, 2002, 67-68, 222-223.

33 Cit. en Justo SERNA y Encarnación GARCÍA, eds., Joan Fuster: nuevos ensayos civiles, Madrid, Espasa Calpe, 2004, 69. Traducción de los autores.
} 
pensamiento sobre la obtención de unos resultados indiscutibles. ${ }^{34}$ España se enfrenta en la actualidad a los mismos grandes retos que se le plantean a la comunidad internacional en todos los frentes; a escala interna, el país ibérico se enfrenta hoy, además, a un cuestionamiento importante y creciente del ordenamiento político y territorial pactado en 1978; guardando las distancias que el tiempo impone, el discurso, o al menos una parte del discurso de Fuster y Marías en aquella época de transición a la democracia parece revelarse de plena actualidad.

${ }^{34}$ Vicent SALVADOR, Fuster o l'estratègia del centaure: per a una anàlisi del discurs fusterià, Picanya, Edicions de Bullent, 1994, 23, 29-30. En el mismo sentido MOLLÀ, op. cit., 23 y Francesc PÉREZ MORAGÓN, Joan Fuster: el contemporani capital, Alzira, Germania, 1994, 10, 13-14, 26. 